Estudos da Língua(gem)

\title{
A entonação de atos de fala interrogativos por uma criança em fase final de aquisição da linguagem em interação com um adulto: uma análise fonopragmática
}

\footnotetext{
La entonación de actos de habla interrogativos por una niña en etapa final de adquisición del lenguaje en interacción con un adulto: un análisis fonopragmático
}

\section{Diego da Silva Vargas*}

Universidade Federal do Estado do Rio de Janeiro (UNIRIO/Brasil)

\begin{abstract}
RESUMO
Este trabalho busca descrever as perguntas totais produzidas por uma criança de 3 anos e 5 meses em interação lúdica com um adulto. Seu objetivo era classificar os enunciados nas categorias de atos de fala definidas por Raso (2012) e descrever seu padrão prosódico. Entretanto, os fatores que interferiram na análise (criança em fase de aquisição, fala espontânea, pouca descrição das categorias analisadas) complexificaram o estudo e aqui pretendemos levantar postulações iniciais que possam contribuir para estudos sobre a organização do $\mathrm{PB}$ em diferentes atos de fala e sobre a aquisição da prosódia no PB.
\end{abstract}

PALAVRAS-CHAVE: Entonação. Pragmática. Aquisição da linguagem. Atos de fala.

\section{RESUMEN}

Este trabajo busca describir las preguntas totales realizadas por una niña de 3 años y 5 meses en una interacción lúdica con un adulto. Su objetivo era clasificar tales preguntas en las categorías de actos de habla definidas por Raso (2012) y describir su patrón prosódico. Sin embargo, los factores que interfieren en el análisis (niña en etapa de adquisición, habla espontánea,

* Sobre o autor ver página 23 .

\begin{tabular}{l|l|l|l|l}
\hline Estudos da Língua(gem) & Vitória da Conquista & v. 15, n. 2 & p. 7-23 & Dezembro de 2017 \\
\hline
\end{tabular}

DOI: https://doi.org/10.22481/el.v15i2.3537

ISSN versão online: 1982-0534 


\begin{abstract}
poca descripción de las categorías analizadas) complejificaron el estudio y aqui pretendemos plantear ideas iniciales que puedan contribuir para estudios sobre la organización de la lengua portuguesa en distintos actos de habla y sobre la adquisición de la prosodia en el portugués en Brasil.
\end{abstract}

PALABRAS CLAVE: Entonación. Pragmática. Adquisición del linguaje. actos de habla.

\title{
1 Introdução
}

O estudo da entonação em diálogos espontâneos adulto-criança é uma área pouco explorada em português e, em espacial, no português do Brasil. Assim, este trabalho busca construir relações iniciais entre estudos em prosódia, em pragmática e em aquisição da linguagem, por meio da análise prosódica de atos de fala realizados por uma criança em fase de aquisição, em uma interação lúdica com um adulto. Seu objetivo é, especificamente, descrever, dentre os enunciados interrogativos, os que se definem como perguntas totais (FÓNAGY, 1993). Nesse sentido, cabe lembrar que a interface entre os estudos em pragmática e os estudos em prosódia já vem sendo construída há algum tempo, porém, de modo geral, no Brasil, tais estudos têm sido realizados com adultos e seus resultados revelam padrões constituídos da língua.

Nesse sentido, Barbosa (2010, p. 390) lembra-nos do importante "papel da prosódia na aquisição, sobretudo como primeiro vetor de coesão textual e dialogia". Dessa forma, cabe lembrar que no processo de aquisição, "o que se adquire não é pura e simplesmente uma língua, com suas regras especificamente linguísticas, mas todo um sistema de práticas e valores, crenças e interesses a ele associados. É neste sentido que podemos falar da aquisição de uma pragmática" (MARCONDES, 1992, p. 42)

Portanto, mesmo sabendo que há trabalhos que sugerem que "o inventário adulto de acentos nucleares e tons fronteira e os respectivos padrões de alinhamento de F0 são dominados muito cedo pelas crianças, em alguns casos antes mesmo ou por volta dos 2,0" (MATA; SANTOS, 2010), acreditamos ser interessante o desenvolvimento de uma descrição de alguns enunciados, categorizados em atos de fala, como forma de contribuir para estudos sobre o processo de aquisição de prosódia. Além disso, torna-se uma oportunidade de problematizar descrições e categorizações já feitas, contribuindo, de alguma maneira, para a descrição dos falares que constituem o português do Brasil.

\section{A pragmática e a teoria dos atos de fala}

Dentre os estudos desenvolvidos dentro da Pragmática, este trabalho está focado na chamada teoria dos atos de fala. Austin $(1990 ; 1998)$ discute a 
materialidade e a historicidade das palavras, desenvolvendo uma teoria que observa a linguagem não como descrição do mundo, mas como ação (dizer é fazer), como uma atividade que se constrói na própria interação entre os interlocutores. Assim, considera-se os enunciados como ações sobre o real, pois "quando falamos, não fazemos apenas declarações, mas fazemos coisas como: ordenar, perguntar, pedir, desculpar-nos, lamentar, rogar, julgar, reclamar, etc." (WILSON, 2010, p. 92).

Austin (1990; 1998) estabelece uma distinção entre os atos de fala que realizam ações ao serem ditos e somente porque são ditos (os chamados performativos) e os que realizam afirmações, dizendo algo sobre um estado de coisas no mundo (os chamados constativos). Aprofundando essa diferenciação, Austin (1990) postula uma separação entre níveis de ação linguística, posto que, quando dizemos algo, estaríamos realizando três tipos de atos simultaneamente: a) um ato locutório, representado pelo conteúdo linguístico que usamos (fonético, sintático e referencial); b) um ato ilocutório, no qual se encontraria a força performativa, relacionada ao modo de dizer algo, refletindo a posição do locutor em relação ao que diz; e c) um ato perlocutório, relacionado aos efeitos causados em quem ouve, referindo-se às consequências do que se diz em relação aos alocutários, ao próprio locutor ou sobre outras pessoas.

Objetivando dar continuidade aos estudos de Austin, Searle (1976; 1981) buscou construir um estudo sobre a teoria dos atos de fala focado em aspectos linguísticos. Segundo o teórico, a unidade básica da comunicação linguística humana é o ato ilocucionário. Partindo dessa noção, busca quantificar os tipos de atos ilocucionários e classificá-los em certas categorias ou tipos básicos (SEARLE, 1976). Haveria, assim, um número limitado de ações que podemos executar com a linguagem, ainda que possam ocorrer simultaneamente. $\mathrm{O}$ autor aponta que Austin já havia desenvolvido uma taxonomia de atos de fala (cf. AUSTIN, 1990), porém, ela representaria muito mais uma lista de verbos ilocucionários do que de atos ilocucionários (SEARLE, 1976) e enfatiza que os verbos ilocucionários são parte de uma língua particular e funcionam como um bom guia, mas nem sempre seguro, para as diferenças entre os atos ilocucionários.

Partindo da noção de que é preciso diferenciar a força ilocucionária do conteúdo proposicional de um enunciado, Searle (1976) classifica os atos de fala em cinco grandes categorias: a) assertivos (representatives) - declarações sobre como as coisas são, envolvendo noções de verdade ou falsidade e buscando convencer o ouvinte de algo; b) diretivos (directives) - tentativas de levarmos as pessoas a fazerem algo para nós; c) expressivos (expressives) - expressão de sentimentos e atitudes; d) comissivos (comissives) - o desejo do falante de produzir uma mudança de estado por meio do que se diz; e) declarativos (declaratives) - dependem de situações extralinguísticas para que sejam validados, uma vez que se relacionam a instituições em que falantes e ouvintes possuem um papel rigidamente determinado.

Além disso, Searle nos chama a atenção para uma diferença fundamental no desenvolvimento de sua teoria: a diferença entre ato ilocutório e força ilocutória ou ilocucional. Como nos explica Wilson (2010, p. 94), "ato ilocutório é o ato que corresponde às ações que podem ser realizadas; força 
ilocutória ou ilocucional é o componente que determina a diferença entre um ato e outro, o que traduz a particularidade de cada ato". Para Searle, haveria linguisticamente marcadores dessa força ilocucional. Wilson (2010, p. 95) cita que, em português, esses marcadores podem ser representados pela ordem das palavras, pelo acento tônico, pela entonação, pela pontuação, pelos modos verbais ou pelo uso de verbos performativos, por exemplo. Searle (1984) salienta também que nem sempre os atos de fala expressam o significado pretendido por quem o executa, sendo possível a realização de atos de fala chamados indiretos, como, por exemplo, a realização de uma ordem por meio de uma pergunta.

Mais recentemente, Raso (2012, p. 100) desenvolve algumas críticas em relação aos estudos de Searle. Segundo ele, "quando se realizam experimentos com base em corpus, essa visão não parece adequada para capturar dados reais". Isso porque a conversação cotidiana não é contemplada pela lista de verbos performativos e pelos critérios com os quais Searle fez sua categorização: "Searle acaba dando grande importância para atos que se realizam muito raramente ou simplesmente não se realizam em corpora; por outro, atos de fala muito comuns e frequentes não são identificados através do princípio do verbo performativo" (RASO, 2012, p. 100). A principal razão para isso seria, segundo o autor, o fato de que essa teoria não leva em consideração a prosódia. Além disso, ele lembra que esses estudos não são feitos com base em corpora. Assim, faz-se necessária uma articulação entre a chamada teoria dos atos de fala e os estudos em prosódia, no sentido de aprofundar ambas as áreas de estudos, bem como a própria compreensão do funcionamento da linguagem em uso.

\section{Os estudos em prosódia e a teoria dos atos de fala}

Considerando-se a fala como uma sucessão de sons ou de segmentos, pode-se dizer que a prosódia estuda os chamados fenômenos suprassegmentais. Neste trabalho, focamos a entonação, que pode ser entendida como "o estudo das modulações de altura (pitch) ao longo dos enunciados" (BARBOSA, 2010, p.391). Como já dito, a entonação, em língua portuguesa, é um marcador de força ilocucional (WILSON, 2010). Assim, "a prosódia constitui a interface entre o ato locutivo e o ato ilocutivo que cumprem, simultaneamente, o ato de fala. [...] Através da prosódia atribuímos também a essas unidades um determinado valor comunicativo" (RASO, 2012, p. 99). Partindo então dessa concepção, entendemos, que os enunciados se diferem a partir do conteúdo ilocucionário que veiculam e o significante que carrega esses diferentes sentidos é, então, a prosódia (RASO, 2012). Entretanto, há que se lembrar que não existe uma correlação unívoca entre atos de fala e perfis prosódicos e que, portanto,

a realização de um ato de fala não depende unicamente do perfil prosódico realizado, mesmo este sendo um traço necessário para a interpretação pragmática. [...] O perfil prosódico é acompanhado, também, de uma série de traços pragmáticos e cognitivos (RASO, 2012, p. 104). 
Neste trabalho, estamos focando nossa análise na "classe modal das frases interrogativas" (FÓNAGY, 1993), entendendo que ela pode abarcar uma série de enunciados cujos perfis prosódicos, em língua portuguesa, podem coincidir ou não. $\mathrm{Na}$ tentativa de observar a classe modal dos enunciados interrogativos, Ladányi (1965, apud FÓNAGY, 1993) apresenta uma interessante matriz pragmática de análise, levando em conta a relação entre o enunciado e os interlocutores. Assim teríamos quatro tipos de questões: (1) da qual tanto locutor como interlocutor sabem a resposta; (2) da qual apenas o locutor sabe a resposta; (3) da qual apenas o interlocutor sabe a resposta; e (4) da qual nem locutor nem interlocutor sabem a resposta.

Apesar de não usar o termo, podemos dizer que o autor defende a ideia de que, em cada categoria dessas, encontram-se vários possíveis atos de fala. Fónagy (19933, p. 36) explica que "em muitas línguas a entoação basta para transformar uma asserção em interrogação", como em português. Em relação às questões totais, seus meios de expressão poderiam variar nas diferentes línguas ou mesmo dentro de uma só língua: ausência ou presença de partículas, inversão de termos, um gesto ou uma configuração melódica. Já as questões parciais necessitariam sempre de signos de dupla articulação, já que deve orientar as respostas numa direção precisa.

\section{$4 O$ estudo: descrição, análise e discussões}

Nossa informante é uma menina carioca, filha de pais cariocas, de 3 anos e 5 meses de idade, cuja voz foi gravada durante cerca de cinquenta minutos de interação, durante a realização de atividades lúdicas, com um falante adulto também carioca. Essa gravação foi submetida ao programa computacional de análise acústica PRAAT (BOERSMA; WEENINK, 1993; 2010), sendo os enunciados interrogativos executados pela criança destacados para encontrar seus contornos melódicos. Aqui, cabe ressaltar que, muitos "linguistas estão se dedicando às situações de "exceção", fundamentais na compreensão da linguagem em uso" (PINTO, 2009, p. 49). Assim, é objetivo também dos estudos pragmáticos, ao analisar a linguagem em uso, não descartar elementos não convencionais (PINTO, 2009, p. 49). Portanto, foram excluídos apenas os enunciados que não puderam ser analisados devido a ruídos e sobreposições. Foram encontrados, então, 13 enunciados interrogativos: (a) oito perguntas totais; e (b) dois pedidos de confirmação. Também foram encontradas duas "tag questions" (FÓNAGY, 1993) não analisadas por falta de espaço neste trabalho.

Assim, todos os atos de fala analisados posteriormente se encontram na classe dos diretivos, tanto na classificação de Searle (1976) como na de Raso (2012). Observa-se, porém, que essa classificação em questões totais e de confirmação será revista adiante. De início, vale lembrar, como o fazem Mata e Santos (2010, p. 1) que: 
As interrogativas, como se sabe, podem ter diferentes valores pragmáticos. [...] As interrogativas globais podem funcionar como pedidos de confirmação [...]. Neste caso, dispomos do contexto discursivo como pista para a identificação da interrogativa como confirmativa. Uma questão que se levanta é a de saber até que ponto poderemos também contar com pistas entoacionais para a identificação deste tipo de interrogativas.

As perguntas totais, segundo Fónagy (2012), se definem por admitir apenas duas respostas do interlocutor: sim ou não. Como ele não apresenta uma classificação de atos de fala, é possível postular que essa seja uma categoria ampla de enunciados na qual se incluem diferentes atos de fala. Entretanto, Raso (2013) apresenta-a juntamente a uma série de atos de fala diretivos que poderiam, a nosso ver, manifestar-se como perguntas totais ("pedido de confirmação" e "convite", por exemplo). Como a classificação em atos de fala e sua descrição prosódica estão em construção, trabalharemos aqui com algumas problematizações, no sentido de contribuir para a construção desse debate.

A primeira pergunta total foi encontrada ao início da gravação. Como resposta a um pedido de informação, seguido de ordem, do adulto ("Como que é esse jogo? Me explica.”), a menina produziu a seguinte pergunta total paroxítona: "Depois tu joga?". Trata-se de uma pergunta total, pois o interlocutor pode respondê-la com um sim ou um não. Entretanto, analisandoa no contexto, também podemos considerar que mais do que um sim/não, a criança deseja confirmar uma informação anteriormente posta na conversa: a de que o adulto jogaria com ela.

Trabalhos anteriores já descreveram as perguntas totais no português do Brasil como sendo de natureza melódica essencialmente ascendente, em oposição às parciais e alternativas, que seriam de natureza ascendentedescendente (GARCIA, 1986). Assim, o que as distinguiria de um enunciado de modalidade assertiva, por exemplo, caso não haja nenhuma marca morfológica ou sintática, seria o tom mais alto ao final do enunciado (FONAGY, 1993; MORAES, 2008). Moraes (2008) aponta, então, que:

uma questão total neutra é caracterizada por uma subida melódica na primeira sílaba tônica, situada em nível médio, ligeiramente maior do que a observada nas declarações. Este aumento frequentemente atinge a sílaba pós-tônica, e é seguido por uma queda contínua até a sílaba pré-tônica final, que se encontra em um nível baixo, e por uma subida melódica na sílaba tônica final, caindo novamente em eventuais sílabas pós-tônicas (tradução nossa) (MOARES, 2008, p. 394).

Cabe lembrar que há estudos que apontam para diferenças entre realizações fonéticas de questões totais em diferentes regiões do Brasil 
(CUNHA, 2000; SILVA, 2011). Silva (2011) diferencia em seu trabalho um padrão ascendente, produzido por falantes do norte, de um padrão circunflexo, produzido por falantes do sul. Assim, em uma análise centrada na fala carioca, Couto et. al. (2010, p. 604) descreveram que, em relação às interrogativas totais, no "o padrão mais frequente apresenta subida da pré-tônica para tônica seguida de queda da tônica para pós-tônica, ou seja, encontramos na maioria dos casos o padrão melódico circunflexo". Dessa forma, era de se esperar que esse enunciado também seguisse esse padrão melódico. Entretanto, em "depois tu joga", encontramos um padrão levemente diferenciado: uma leve subida na primeira pré-tônica e uma descida melódica até a última tônica, quando, apresenta-se uma subida melódica mais intensa acompanhada de uma descida que se estende até a pós-tônica:

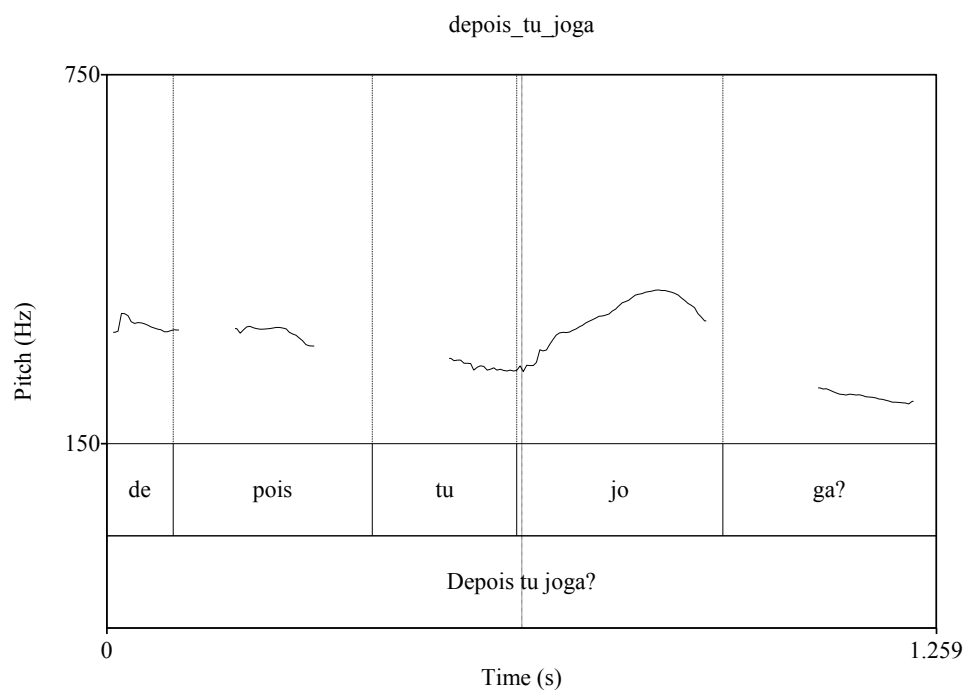

Figura 1. Representação do enunciado "depois tu joga"

Poderíamos postular, então, que se trata de outro ato de fala, como o pedido de confirmação, por exemplo. Em relação a essa categoria de atos de fala, Mata e Santos (2010, p. 2) apresenta uma subdivisão por meio da qual diferencia as que se relacionam a "confirmação da compreensão" das que se relacionam a "confirmação da percepção":

no caso das interrogativas de "confirmação da compreensão", a interrogativa centra-se no significado de um enunciado que a precede; no caso de interrogativas de "confirmação da percepção", o que está em causa é a descodificação do sinal e, portanto, a confirmação do que foi pronunciado. [...] no caso de uma confirmativa de "compreensão", qualquer das respostas apresentadas no exemplo será possível [resposta SIM, resposta SER, 
resposta verbal]. Contudo, se o interlocutor interpretar a interrogativa como uma confirmativa de "percepção", não usará a resposta verbal (MATA; SANTOS, 2010, p. 2).

Em relação ao português europeu, as autoras apresentam dois padrões entonacionais diferentes para cada uma dessas categorias. Em relação ao português do Brasil, encontramos apenas uma descrição (MORAES, 2008). Entendendo o pedido de confirmação como uma questão para a qual se espera uma resposta de mesma polaridade da proposição contida na pergunta, Moraes (2008) apresenta, então, o seguinte padrão entonacional para o português do Brasil a partir da fala de cariocas: há uma subida para um nível tonal extra-alto na sílaba pré-tônica final, seguido por uma queda para um nível baixo na tônica e que permanece assim nas sílabas pós-tônicas. Ele salienta, entretanto que a forma do contorno intrassilábico da sílaba tônica final é diferente, assumindo uma configuração de queda acentuada.

Assim, observa-se que, mesmo que dentro da classificação apresentada por Mata e Santos (2010) o enunciado "depois tu joga" pudesse ser classificado como um pedido de confirmação de compreensão (A: depois tu joga? B: jogo), a curva entonacional apresentada também não se encaixa no padrão descrito por Moraes (2008), aproximando-se, na verdade muito mais do padrão das questões totais. Poderíamos, portanto, postular três hipóteses: (a) a curva melódica apresentada é uma variação da curva padrão do português do Brasil falado no Rio de Janeiro; (b) trata-se de algum outro ato de fala ainda não descrito; ou (c) por encontrar-se em período de aquisição da linguagem, a menina informante não tenha desenvolvido o padrão da questão total.

Observando-se as curvas dos outros enunciados categorizados como questões totais, podemos observar um comportamento mais semelhante ao do padrão apresentado por Moraes (2008), mas ainda não idêntico. Em "a caixinha vai ficar ali”, cuja enunciação se deu em um contexto que não admitia a possibilidade de ser um pedido de confirmação, apresenta-se a seguinte configuração melódica: há uma leve subida na primeira tônica do enunciado seguida de uma queda melódica na pós-tônica que a acompanha, a qual se segue uma nova subida leve que se estende até a última pré-tônica, onde se encontra uma nova queda acompanhada de uma grande subida melódica na tônica final. Como se trata de uma questão total oxítona, não há como haver nenhuma queda que acompanhe a tônica final e complete o ciclo descrito por Moraes (2008), como se pode ver na imagem abaixo: 
a_caixinha_vai_ficar_ali

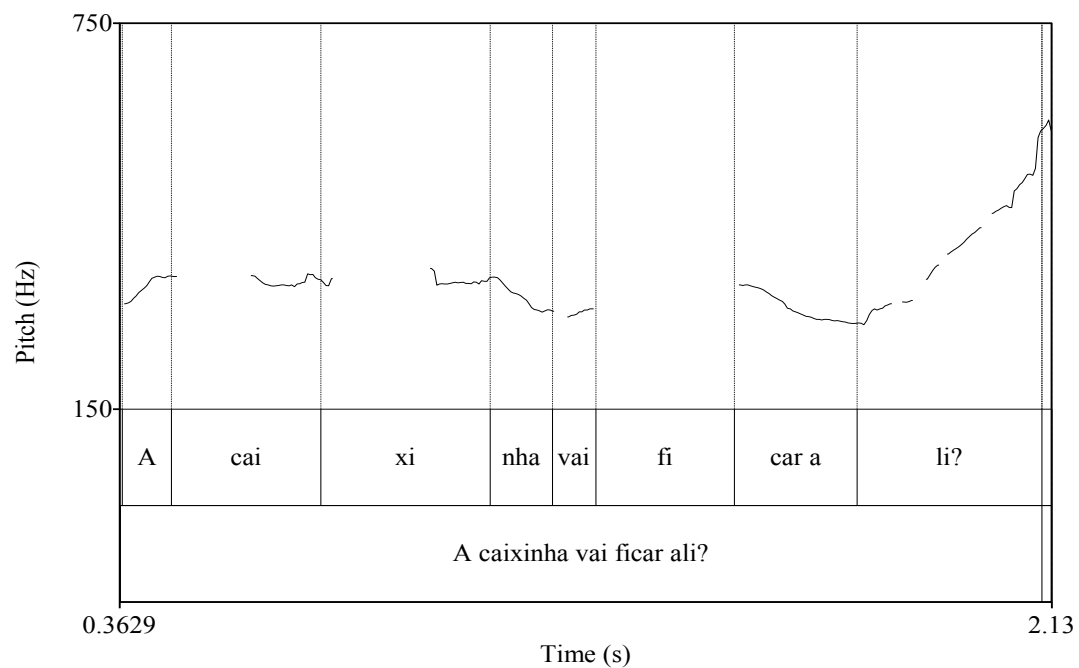

Figura 2. Representação do enunciado "a caixinha vai ficar ali”

Outro enunciado semelhante se apresenta. Em "o saquinho vai ficar ali", apresenta-se a seguinte configuração melódica: há uma leve subida nas primeiras pré-tônicas que se estende até a primeira tônica do enunciado seguida de uma queda tonal na pós-tônica que a acompanha, a qual se segue, igualmente ao enunciado anterior, uma nova subida leve que se estende até a última pré-tônica, na qual se apresenta uma nova queda acompanhada de uma grande subida melódica na tônica final, que, diferentemente do enunciado anterior, já apresenta em si uma leve queda melódica.

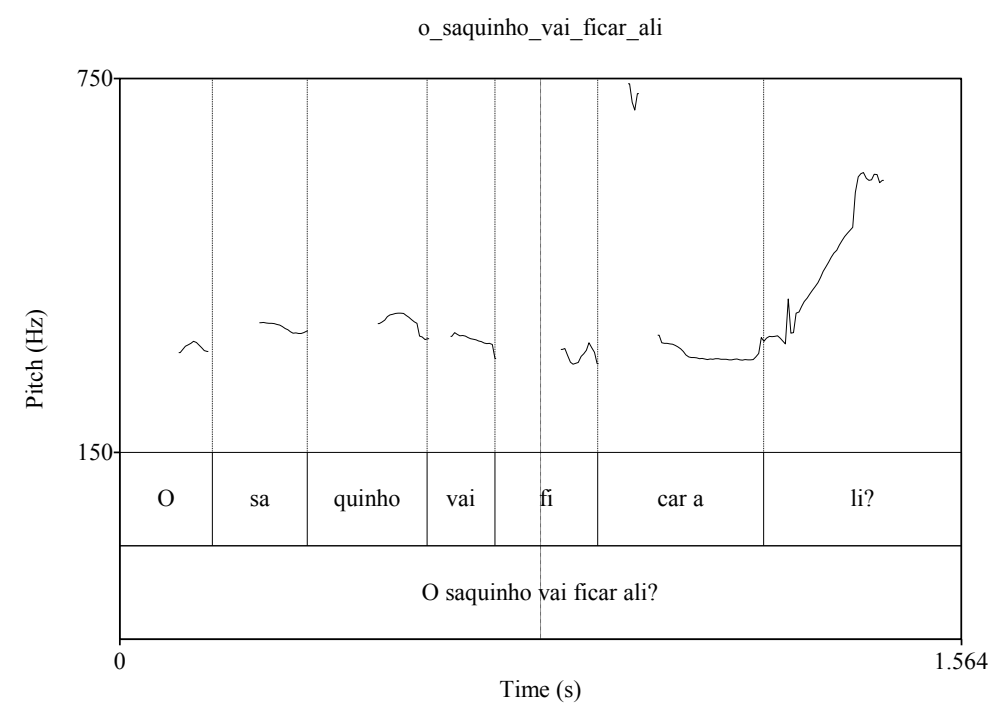

Figura 3. Representação do enunciado "o saquinho vai ficar ali" 
Em seguida, apresentaremos alguns enunciados interrogativos que, em nossa visão, não podem ser classificados pragmaticamente como pedidos de confirmação ou questões totais, visto que mais do que uma resposta sim/ não, solicitam ao interlocutor uma autorização para fazer algo, o que nos leva a classificá-los como um "pedido de autorização". Trata-se de um ato de fala comum na fala infantil dirigida a adultos, talvez ainda não descrito por aparecer neste tipo de interação não muito presente em análises fonopragmáticas. Ele ocorre, por exemplo, quando, ao constatar que não tinha nenhuma das peças de dominó que poderia jogar, a criança pede autorização ao adulto para jogar outra peça, enunciando: "não tenho nenhuma das duas, pode ser esse".

Apesar de não ser o foco deste trabalho, podemos observar que a asserção que antecede a pergunta apresenta uma configuração melódica muito peculiar, com elevadas subidas melódicas alternadas até que ocorre uma forte queda na última pré-tônica e que se estende até o início do enunciado interrogativo, que apresenta a seguinte configuração: uma subida melódica na primeira tônica que se estende até a tônica final, quando, então, apresenta-se uma queda relativamente forte, seguida de uma leve subida melódica na pôstônica que a acompanha. Se observarmos a configuração dos dois atos em conjunto, podemos observar que ela se assemelha ao padrão melódico que Moraes (2008) apresenta para o que ele denomina como sendo o do "pedido" ou da "pergunta retórica", o que pode reforçar a nossa visão de que se trata de um ato de fala muito mais próximo do que seria um pedido (de autorização?) do que de uma questão total.

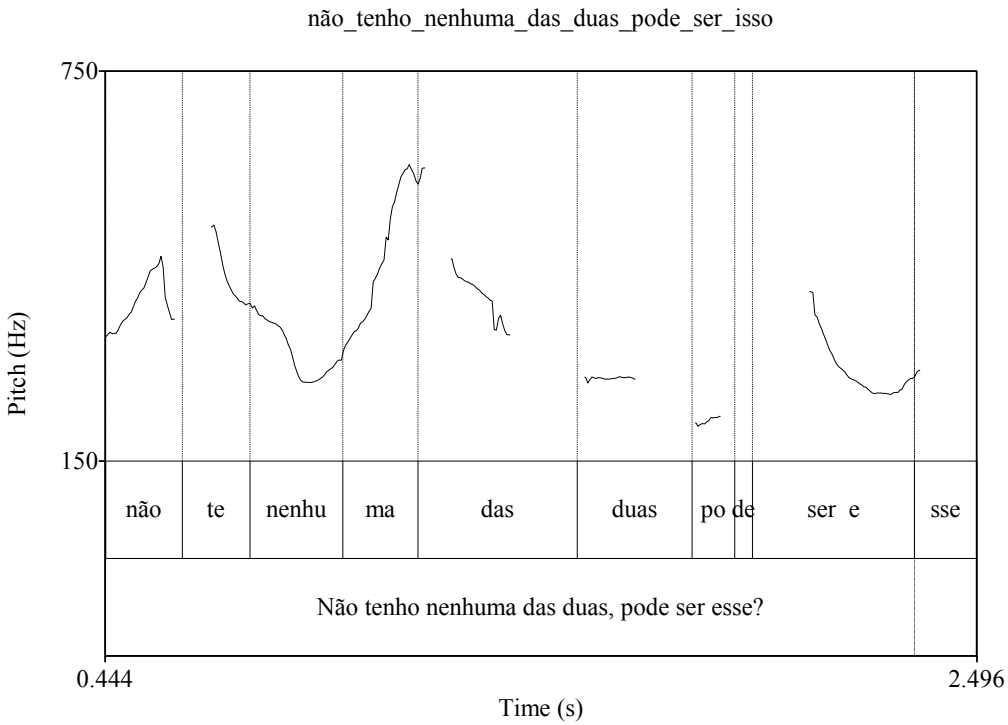

Figura 4. Representação do enunciado "não tenho nenhuma das duas, pode ser esse"

Podemos observar que uma configuração muito semelhante ocorre em "eu tenho dois, pode ser", enunciado por meio do qual a menina pede a autorização para jogar duas peças de uma só vez na partida de dominó. 
Podemos observar na asserção "eu tenho dois" que acompanha a questão total um padrão semelhante ao descrito por Moraes (2008) para as asserções de ênfase constrastiva, com uma elevação de nível extra-alto até a pós-tônica final e uma queda para um baixo nível na tônica final. Já o enunciado interrogativo apresenta uma leve subida acompanhada de uma queda na primeira tônica e uma nova subida mais elevada na pós-tônica, a qual se segue uma grande queda na tônica final. Assim, nesse enunciado, como no anterior, observa-se uma subida e queda dupla (na assertiva e na interrogativa), sendo a elevação da assertiva mais alta que a da interrogativa.

eu_tenho_dois_pode_ser

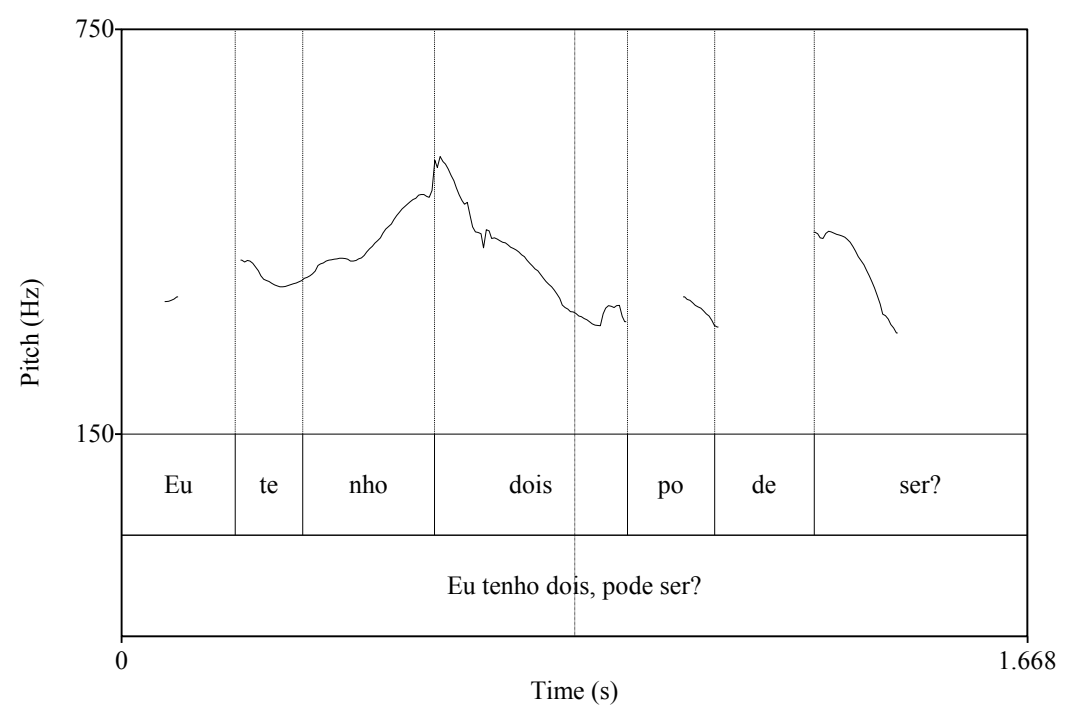

Figura 5. Representação do enunciado "eu tenho dois pode ser"

Semelhante configuração apresenta o enunciado "nós dois, pode ser", por meio do qual a criança propõe que ela e o adulto montem um quebra-cabeça. Como nos enunciados anteriores, há uma elevação melódica e uma queda no enunciado assertivo que se estende até a primeira tônica do enunciado interrogativo, à qual se segue uma elevação de alto nível na pós-tônica acompanhada de uma queda na tônica final. 


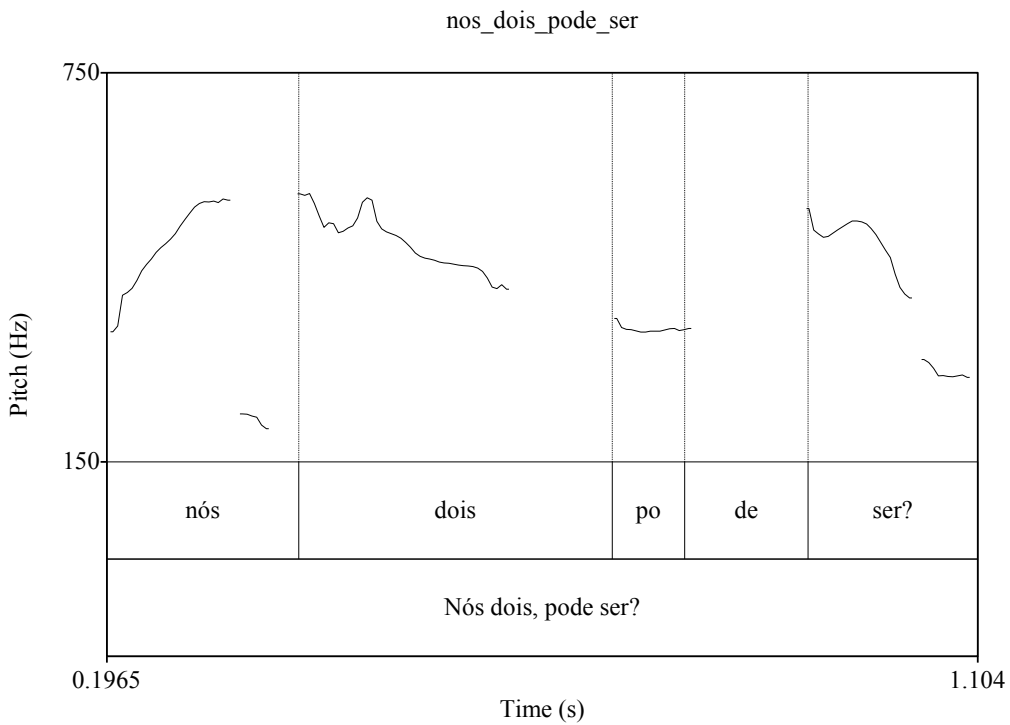

Figura 6. Representação do enunciado "nós dois, pode ser"

O mesmo se observa no enunciado "eu posso comer aqui”, que também contextualmente não pode ser classificado como pedido de confirmação. Também não poderia ser incluído na categoria das questões totais, como sua própria configuração melódica aponta: trata-se de um enunciado interrogativo cuja subida melódica inicial se dá da primeira pré-tônica para a primeira tônica, na qual se apresenta uma leve queda acompanhada de uma leve subida e uma nova queda que se estende até a última pré-tônica, na qual se inicia um processo de ascensão da curva melódica e que se estende até a tônica final, onde mesmo ocorre a queda final. Como se trata de uma oxítona, o processo de leve subida apresentado no enunciado anterior e nos pedidos descritos por Moraes (2008) não se completa, apesar de iniciar-se na própria tônica final. 
eu_posso_comer_aqui

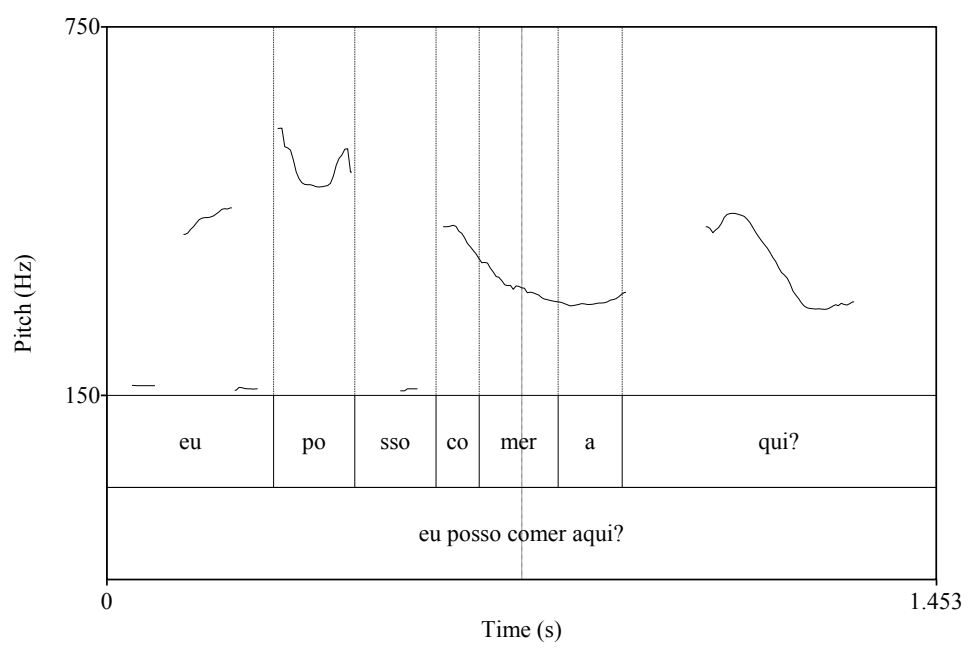

Figura 7. Representação do enunciado "eu posso comer aqui”

Além dos atos de fala anteriores, encontramos também uma questão total que se diferencia bastante do padrão apresentado em Moraes (2008). Observase que a criança utiliza-se de uma estratégia de focalização acrescentando o termo "esse" ao final de seu enunciado, o qual se configura por meio de uma curva ascendente-descendente em sua sílaba tônica. Tal estratégia poderia ser a responsável pela alteração da configuração dessa questão total. Entretanto, observa-se que ocorre uma elevação de alto nível da curva melódica nas prétônicas que antecedem a última pré-tônica.

Assim, as hipóteses postuladas em relação ao primeiro enunciado poderiam ser retomadas, posto que, novamente poderíamos considerar que se trata de uma variação do padrão entonacional das questões totais, de uma não completude no processo de aquisição ou da enunciação de outro ato de fala, que, nesse caso, poderia ser classificado como um oferecimento em forma de questão total, já que a criança oferece seu colo para que se apoiem as peças que estavam de posse do interlocutor adulto. 
quer que fique no meu colo esse

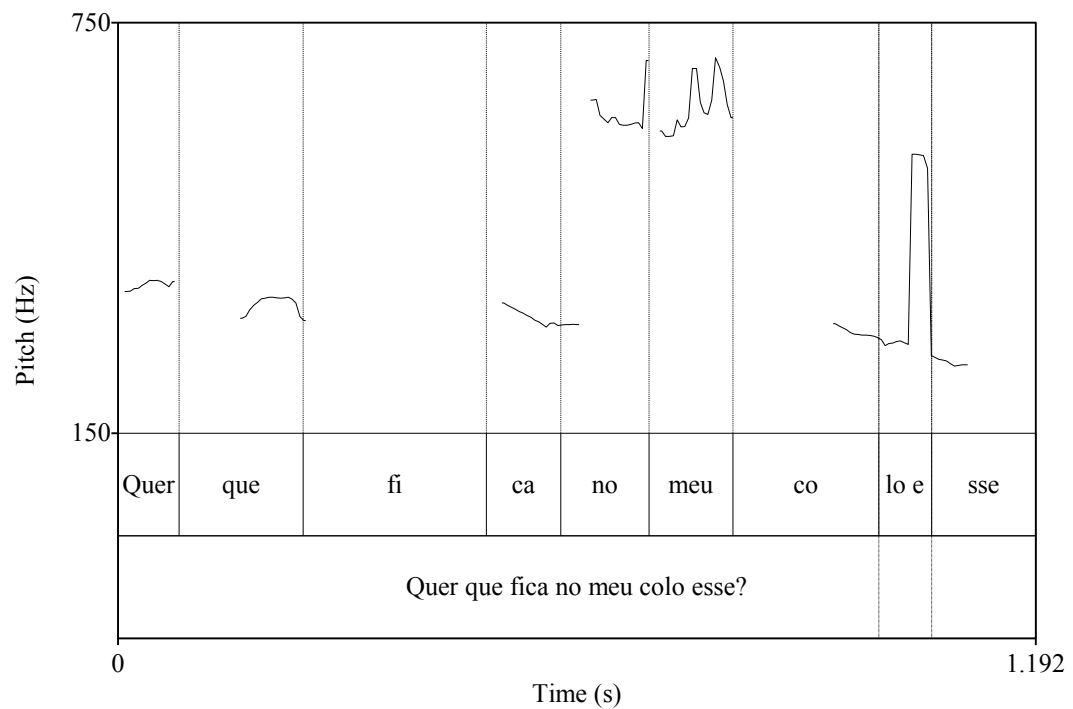

Figura 8. Representação do enunciado "quer que fica no meu colo esse"

Por fim, analisamos, então, os atos de fala que essencialmente se caracterizariam como pedidos de confirmação. Ao ser informada de que deveria retirar uma peça antes de iniciar o jogo, a criança pergunta: "primeiro" e, ao não obter a resposta que queria, repete a mesma questão, porém com mais ênfase prosódica como se pode ver na imagem abaixo. Entretanto, a configuração melódica de ambos os enunciados se aproxima muito mais do padrão descrito para as questões totais do que para os pedidos de confirmação, uma vez que ocorre uma pequena subida melódica na pré-tônica acompanhada de uma também pequena queda e de uma elevada subida melódica na tônica, acompanhada de uma queda também elevada na pós-tônica. 


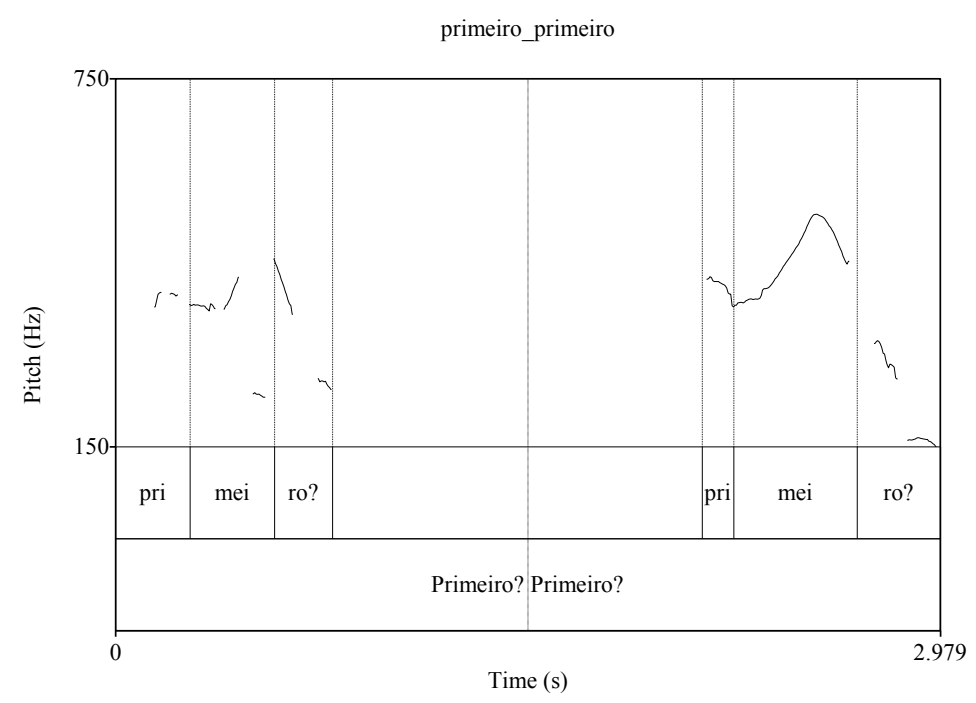

Figura 9. Representação do enunciado "primeiro primeiro"

\section{Considerações finais}

Neste trabalho, desenvolvemos uma análise inicial dos enunciados interrogativos produzidos por uma criança do sexo feminino em fase final de aquisição da linguagem. Nosso objetivo era classificar esses enunciados em diversas categorias de atos de fala, segundo a classificação apresentada em Raso (2012) e descrever o padrão prosódico de cada uma dessas categorias, sem deixar de levar em consideração o contexto em que os enunciados analisados foram emitidos.

Como se pode observar ao longo da análise apresentada, a complexidade de fatores que interferiram nesta análise (criança em fase de aquisição, fala em contexto de uso espontâneo, pouca descrição das categorias trabalhadas) impediu que alcançássemos plenamente nossos objetivos categorizar e descrever. Entretanto, acreditamos que as postulações aqui levantadas, tanto em relação às categorizações já apresentadas em outros trabalhos como em relação às descrições aqui feitas, podem contribuir tanto para os trabalhos que buscam compreender a organização da língua portuguesa em diferentes atos de fala, como para os que pretendem investigar o processo de aquisição da prosódia em falantes do português do Brasil.

\section{REFERÊNCIAS}

AUSTIN, J. L. Quando dizer é fazer: palavras e ações. Porto Alegre: Artes Médicas, 1990.

AUSTIN, J. L. Performativo-constativo. In: OTTONI, P. Visão performativa da linguagem. Campinas-SP, Editora da Unicamp, 1998. p. 107-144 
BARBOSA, P. A. Prosódia: uma entrevista com Plínio A. Barbosa. ReVEL, v.8, n.15, 2010.

BOERSMA, P.; WEENINK, D. Praat 1993-2010. Disponível em: http://www.fon.hum.uva.nl/praat/. Acesso em 25 de agosto de 2016.

COUTO, L. C.; FIGUEIREDO, N. S.; PINTO, M. S.; SOSA, J. M. Pragmática intercultural e entoação: os enunciados interrogativos (perguntas) em português e em espanhol. Anais do I CIPLOM, Foz do Iguaçu, 2010.

CUNHA, C. S.. Entoação regional no português do Brasil. Tese de Doutoramento em Língua Portuguesa. Rio de Janeiro, Faculdade de Letras, UFRJ, 2000.

FÓNAGY, I. As funções modais da entoação. Cadernos de Estudos Linguísticos, Campinas, (25): 25-65, Jul/dez, 1993.

GARCIA, I. W. Um estudo sobre a entonação da frase interrogativa na língua portuguesa culta: uma comparação entre dois tipos de elocução. Organon, Porto Alegre, v.15, n. 15, p. 51-64, 1986.

WILSON, V. Motivações Pragmáticas. In: MARTELOTTA, M. E. Manual de Linguística. São Paulo: Ed. Contexto, 2010.

MARCONDES, D. Filosofia, linguagem e comunicação. São Paulo: Ed. Cortez, 1992.

MATA, A. I; SANTOS, A. L. Perguntas confirmativas em diálogos adultocriança: pistas entoacionais. In: Textos Seleccionados do XXV Encontro APL. Porto, APL: 2010, pp.589-605.

MORAES, J. A. The Pitch Accents in brazilian portuguese: analysis by synthesis. In: Fourth Conference on Speech Prosody, 2008, Campinas. Proceedings of the Speech Prosody. Campinas: Unicamp, 2008. p. 389-397.

PINTO, J. P. Pragmática. In: Introdução à linguística 2 - domínios e fronteiras. São Paulo: Ed. Cortez, 2009.

RASO, T. O C-ORAL-BRASIL e a teoria da língua em ato. In: RASO, T; MELLO, H. C-ORAL-BRASIL I: Corpus de referência do português brasileiro falado informal. Ed. UFMG, 2012.

SEARLE, J. R. Os actos de fala: um ensaio de filosofia da linguagem. Coimbra: Almedina, 1984.

SEARLE, J. R. A classification of illocutionary acts. Language in Society, v. 5, n.1, p. 1-23, abr. 1976.

SILVA, J. C. B. A Prosódia Regional em Enunciados Interrogativos Espontâneos do Português do Brasil. Revista Gatilho, ano VII, v. 13, set. 2011. 
Publicado em dezembro de 2017.

\section{SOBRE O AUTOR}

Diego da Silva Vargas é professor do Departamento de Didática da Universidade Federal do Estado do Rio de Janeiro (UNIRIO) e doutorando do Programa de Pós-graduação em Letras Neolatinas da Universidade Federal do Rio de Janeiro (UFRJ). Mestre em Letras Vernáculas e bacharel e licenciado em Letras: Português/Espanhol pela mesma universidade.

E-mail: dsvargas04@yahoo.com.br 